\title{
Establishing a postgraduate programme in nutritional epidemiology to strengthen resource capacity, academic leadership and research in the democratic republic of Congo
}

Mapatano Mala Ali ${ }^{1}$, Lyn Haskins ${ }^{2 *}$, Vaughn John ${ }^{3}$, Anne Hatløy ${ }^{4,5}$, Silondile Luthuli², Sphindile Mapumulo ${ }^{2}$, Ingunn M. S. Engebretsen ${ }^{4}$, Thorkild Tylleskär ${ }^{4}$, Paulin Mutombo ${ }^{1}$ and Christiane Horwood ${ }^{2}$

\begin{abstract}
Background: Low- and Middle-income countries (LMIC) face considerable health and nutrition challenges, many of which can be addressed through strong academic leadership and robust research translated into evidence-based practice. A North-South-South partnership between three universities was established to implement a master's programme in nutritional epidemiology at the Kinshasa School of Public Health (KSPH), Democratic Republic of Congo (DRC). The partnership aimed to develop academic leadership and research capacity in the field of nutrition in the DRC. In this article we describe the educational approach and processes used, and discuss successes, challenges, and lessons learned.
\end{abstract}

Methods: Self-administered questionnaires, which included both open and closed questions, were sent to all graduates and students on the master's programme to explore students' experiences and perceptions of all aspects of the educational programme. Quantitative data was analysed using frequencies, and a thematic approach was used to analyse responses to open-ended questions.

Results: A two-year master's programme in Nutritional Epidemiology was established in 2014, and 40 students had graduated by 2020. Key elements included using principles of authentic learning, deployment of students for an internship at a rural residential research site, and support of selected students with bursaries. Academic staff from all partner universities participated in teaching and research supervision.

The curriculum and teaching approach were well received by most students, although a number of challenges were identified. Most students reported benefits from the rural internship experience but were challenged by the isolation of the rural site, and felt unsupported by their supervisors, undermining students' experiences and potentially the quality of the research. Financial barriers were also reported as challenges by students, even among those who received bursaries.

(Continued on next page)

\footnotetext{
*Correspondence: haskins@ukzn.ac.za

${ }^{2}$ Centre for Rural Health, School of Nursing and Public Health, University of KwaZulu-Natal, Durban, South Africa

Full list of author information is available at the end of the article
}

(c) The Author(s). 2021 Open Access This article is licensed under a Creative Commons Attribution 4.0 International License, which permits use, sharing, adaptation, distribution and reproduction in any medium or format, as long as you give appropriate credit to the original author(s) and the source, provide a link to the Creative Commons licence, and indicate if changes were made. The images or other third party material in this article are included in the article's Creative Commons licence, unless indicated otherwise in a credit line to the material. If material is not included in the article's Creative Commons licence and your intended use is not permitted by statutory regulation or exceeds the permitted use, you will need to obtain permission directly from the copyright holder. To view a copy of this licence, visit http://creativecommons.org/licenses/by/4.0/ The Creative Commons Public Domain Dedication waiver (http://creativecommons.org/publicdomain/zero/1.0/) applies to the data made available in this article, unless otherwise stated in a credit line to the data. 
(Continued from previous page)

Conclusion: The partnership was successful in establishing a Master Programme in Nutritional Epidemiology increasing the number of nutrition researchers in the DRC. This approach could be used in other LMIC settings to address health and nutrition challenges.

Keywords: Education, LMIC, Research capacity, Partnerships, North-south-south, Nutrition, Epidemiology, DRC, Africa

\section{Introduction}

Building research capacity in low- and Middle-income countries (LMIC) and embedding skilled researchers into health and management systems to develop evidence-based health policies is fundamental to tackle the substantial health challenges these countries face. Policies firmly based on evidence-based interventions, which are locally relevant and applicable, have the potential to improve health in LMIC and reduce health inequities [1]. The World Health Organization (WHO) has identified developing strong leadership in the global health workforce as a priority, and has established partnerships to strengthen the research infrastructure and capacity in the public health arena in African Universities [2]. This has led to the development of many collaborations between high-income countries, mainly from the global North, and LMICs in the global South, which have played a strong role in developing research capacity. However, there have been concerns that uprooting LMIC students to study in high-income countries may provide students with skills that are not relevant or applicable to their local context [3]. In addition, there may be a brain drain associated with out-of-country training, particularly for long periods, as students become rooted in the host country and fail to return. Another key challenge has been mismatches between the health needs of the South partners and research investments of the North partners, leading to partners in the North driving the research agenda, focusing research activities away from local priorities [4].

In response to these challenges, the focus of these collaborations has shifted towards more equal North-South partnerships and health research capacity building initiatives aimed at supporting demand-driven and locally led research. These partnerships have employed a number of different approaches, including training courses to build and strengthen research skills [5-9], strengthening research infrastructure [6], supporting and training doctoral students $[7,9,10]$, and training master's students who remain in their country of origin [11] or within the African continent [8]. Other approaches have successfully engaged students in international working environments either through nesting students in research projects [10], or with short term exchanges, thus providing the southern partner with a stable locus of expertise within their own country [12].
A variety of technology-based teaching and learning methodologies have recently been introduced. Blended learning, combining face-to-face learning with electronic resources and online interactions, was able to effectively draw on skills in different countries to support global health research capacity building, but set up was costly $[5,13]$. An e-learning approach was successfully able to provide health professionals working in LMIC with the opportunity to obtain a master's degree using entirely online resources on a free open online platform [11]. However, these collaborations remain challenging with unequal power relationships between partners, lack of buy-in and leadership between partners, differing time zones and partner schedules, and technology being new to partners [6].

Nutrition is an important field for health research capacity building, since malnutrition remains a leading cause of ill health globally. Addressing malnutrition is important for achieving Sustainable Development Goal (SDG) goal 2 of zero hunger, and is therefore a key priority in many low-income countries. Nutrition interventions are frequently context-specific, making this a field of study where local research expertise is particularly important to develop and evaluate affordable, acceptable, evidence-based interventions to inform policy. Nutritional epidemiology is a relatively new field of public health and concerns the patterns, causes and solutions to nutrition problems, focusing in particular on the relationship between diet and disease. Skills development in nutritional epidemiology increases capacities to address the burden of nutrition problems, including food insecurity, malnutrition, and micronutrient deficiencies across the lifespan. Few African universities offer postgraduate studies in nutritional epidemiology.

This article describes the approach taken by a North-South-South partnership, to train master's and doctoral students in nutritional epidemiology, at Kinshasa School of Public Health (KSPH), University of Kinshasa (UNIKIN), Democratic Republic of Congo (DRC). The DRC has some of the highest rates of undernutrition globally, and a poor track record in health research $[9,14,15]$. In this paper we focus on the master's programme, describing key concepts underpinning its development and implementation, and describe successes and challenges from the perspectives of the master's students. 


\section{Description of the nutritional epidemiology master's programme}

The 'Growing Partnership for Higher Education and Research in Nutritional Epidemiology in DRC' (GROWNUT) project was a partnership between Centre for International Health $(\mathrm{CIH})$, University of Bergen (Norway), Centre for Rural Health (CRH), University of KwaZulu-Natal (South Africa), and KSPH, UNIKIN (DRC). GROWNUT was established in 2014, in partnership with the DRC National Nutrition Programme (PRONANUT) at the DRC Ministry of Health, to establish a masters programme in nutritional epidemiology at $\mathrm{KSPH}$. The vision of the partnership was to develop a cadre of skilled researchers in DRC with competencies to undertake quality nutrition research to inform evidence-based policies and practices. The partnership was funded by the Norwegian Agency for Development Cooperation through the Norwegian Programme for Capacity Development in Higher Education and Research for Development (NORHED).

\section{Project setting}

The DRC is a low-income country [16] with a population in excess of 84 million people [17]. There is widespread food insecurity in DRC, and more than 2 million children suffer from acute malnutrition and $43 \%$ of children are stunted [18]. Infant mortality of 68 per 1000 live births and under 5 mortality of 91 per 1000 live births are among the highest in the world [19].

Higher education is provided in universities, polytechnics or specialized colleges. A number of public and private universities in the DRC established since the 1950's, offer a wide variety of fields of study at undergraduate and post-graduate levels. Situated within UNIKIN, the $\mathrm{KSPH}$ offered four master's degree programmes. However, there were no courses in nutritional epidemiology in the DRC.

\section{Key elements of the master Programme in nutritional epidemiology}

KSPH typically offers a one-year master's programme. However, for the nutritional epidemiology programme the period of study was extended to two years in line with master's programmes at partner universities. The two-year programme provided students authentic learning opportunities to develop higher learning thinking, depth of knowledge, real-world problem-solving skills and student directed learning $[20,21]$ in the field of nutritional epidemiology.

\section{Curriculum}

Using a constructivist approach, principles of authentic learning framed the development of the curriculum for the master's programme in nutritional epidemiology, which included theory modules delivered in the first year, and a practical internship at a rural site during the second year of study.

The curriculum content combined concepts of nutrition, epidemiology, research methods and data management, while accounting for global issues such as climate change, natural resource management and food security. The theory component consisted of 17 modules, which were co-facilitated by international and local facilitators, bringing together the skills and perspectives of partner institutions. The aim was that the nutritional epidemiology teaching responsibilities would be handed over to local facilitators at $\mathrm{KSPH}$, so ensure sustainability of the programme. However, due to political unrest limiting travel to the DRC, international facilitators were unable to co-facilitate after the second cohort. Students from the third and fourth cohorts travelled to South Africa to attend a module on research proposal development with facilitators from all partner institutions.

Teaching methods employed an adult learning approach focusing more on the learning process and less on the content of the teaching. Working in groups and as individuals, students were actively involved in their own learning, often having to research a particular topic under discussion, and present it in the classroom setting where it was critiqued and discussed by other students and facilitators. Audio-visual presentations brought global challenges to the classroom setting where these were discussed between students and facilitators with expertise in the field.

\section{Rural internship}

A residential rural research site, with accommodation and study facilities, was established in Popokabaka health zone, in Kwango province, approximately $380 \mathrm{~km}$ south-east of Kinshasa. Popokabaka is an area with particularly high rates of malnutrition [22]. Students were deployed in the rural research site for 3-months practical internship and an additional 1-month to collect data for their research projects. The rural internship aimed to build on the theoretical component, with a 'learning by doing' practical component where students observed nutrition conditions first hand in a rural community. Students gained experience of interacting with communities and staff in local health facilities. Facilitators from KSPH regularly visited the students in the rural site to provide support and interactive teaching. During their internship, students gained skills in nutritional assessment, and collected research data.

\section{Students' research projects}

Individual research projects, based on research questions identified by students, formed an important component of the programme. Two supervisors were allocated to 
each student, the main supervisor at KSPH and a cosupervisor from a collaborating university, bringing different perspectives to the students' research. Students were guided through proposal writing, collecting and analysing data, and writing a dissertation. Students defended their dissertation with key leaders in their field present prior to the completion of their degree. UNIKIN conferred the Master in Nutritional Epidemiology when all academic requirements had been met.

\section{Medium language of teaching and learning}

English was adopted as a medium of instruction at the request of the DRC partner, because of perceptions that most nutrition-related research was published in English, and because English was the common language among partners and funders. Employing English as the medium of instruction aimed to strengthen the students' ability to read and contribute to the scientific literature, participate in the discourse in the nutrition field, and set up collaborative networks outside the DRC. Therefore, students enrolling for the Master in Nutritional Epidemiology needed a working knowledge of English, and applicants undertook an assessment examination, that included an English assessment. As French was the medium of instruction for basic schooling and undergraduate teaching in DRC, this may have reduced the number of students applying to the programme.

\section{Provision of bursaries}

Bursaries were provided for selected students; five bursaries were allocated for each cohort, including one to an existing KSPH staff member for internal capacity building. The remaining four bursaries were allocated to vulnerable groups such as students from war-torn areas and female students.

\section{Achievements of the master's programme}

Forty-one students registered for the Master in Nutritional Epidemiology over four cohorts, (Table 1). Three master's students were employed by KSPH, one of whom is currently completing $\mathrm{PhD}$ studies supported by the project.

Forty students graduated with a Master in Nutritional Epidemiology, of whom 34 wrote their thesis in English and six wrote in French. Research topics spanned a

Table 1 Students participating in the nutritional epidemiology master's programme by cohort

\begin{tabular}{lll}
\hline & Year of study & Number of students graduated \\
\hline Cohort 1 & $2014-2016$ & 10 \\
Cohort 2 & $2015-2017$ & 11 (1 failed) \\
Cohort 3 & $2016-2018$ & 12 \\
Cohort 4 & $2017-2019$ & 7 \\
\hline
\end{tabular}

variety of nutritional challenges in DRC and most students (35) collected data at the rural research site. Examples of research topics are shown in Table 2.

Eleven master's students presented research findings at international conferences and five manuscripts to be submitted in academic recognised journals are in preparation by master's students, supported by project staff. As a result of networking at a conference, one master's graduate set up the "Societé Congolaise de Nutrition et d'Alimentation" (SCONUTAL) society, networking with the SUN-DRC movement, a civil organisation to advocate for investment in national food and nutrition programmes and promote research in the field of nutrition.

In addition, a mini- conference was held at the rural research site in February 2019 to provide feedback about research findings to the local community, including representatives from the Health Zone and Administrative Territory, religious representatives, local NGOs, and stakeholders. PhD and master's students and KSPH academic staff presented findings.

On completion of their degree, master's graduates have been employed in a variety of nutrition specific fields such as PRONANUT (4), WHO (1), UNICEF (2) and other non-governmental organisations (5) where they are able to represent the DRC in the international

Table 2 Examples of research undertaken by Nutritional Epidemiology students

Double burden of malnutrition among adolescents in Popokabaka

Positive deviance as an approach for preventing acute malnutrition in rural context of Popokabaka

Evaluation of the Double Burden of Malnutrition: Under nutrition \& overweight / obesity in children under five years in the city of Popokabaka in Kwango (DRC)

Breastfeeding practices among lactating women living in the Health Area of Popokabaka, Kwango Province, DRC

Dietary knowledge and practices during pregnancy among pregnant women and key informants in the rural area of Popokabaka

Exploration of nutrition counselling provided to pulmonary TB patients in Popokabaka Health Zone

Exploration of nutritional counselling for people living with HIV followed up at Popokabaka hospital

Relationship between women's education level and infant feeding practices in Popokabaka health district

Exploring the perception of the Popokabaka population about the choice of sources of drinking water

Barriers to exclusive breastfeeding practices among mothers with children aged 0-6 months in Popokabaka, Kwango Province, DRC

Care-seeking behaviors of mothers/caregivers about acute malnutrition in children under 5 years of age in Popokabaka

Food insecurity as a barrier to antiretroviral therapy in Popokabaka

Knowledge and feeding practices during pregnancy among mothers who delivered a low birth weight infant in the Popokabaka Health Zone

The relationship between breakfast consumption and school performance among school aged children in Lemba municipality 
arena. Others are employed in teaching capacities, not only at the University of Kinshasa (3), but also other universities and training colleges (2). Two graduates have returned to work in Popokabaka, while others work in hospitals, and rural health zones. One student registered for a PhD at UNIKIN and two students have registered for $\mathrm{PhDs}$ at other universities.

\section{Students' evaluation of the master degree in nutritional epidemiology}

\section{Methods}

Study design

A cross-sectional descriptive study was conducted to evaluate the master's programme in nutritional epidemiology from the perspective of students.

\section{Participants}

Forty students who enrolled in the Master Programme in Nutritional Epidemiology between 2014 and 2018 were invited to participate in the survey, including 32 graduates and eight currently enrolled students. All participants had completed the learning components of the programme. One student who failed the theory modules was excluded from the evaluation.

\section{Data collection tools}

A quantitative questionnaire was developed with both closed and open-ended questions. Participants were requested to rate the quality of all elements of the master's programme using Likert-type scales (Fig. 1), and asked to agree or disagree with a series of statements relating to the quality of the master's programme (Fig. 2). Open ended questions allowed students to comment in their own words about what they valued most or least about the different components of the master's programme. Questionnaires were developed in English and translated into French. Students were requested to respond in the language of their choice.

\section{Data collection and management}

Self-administered questionnaires were emailed to all 40 students requesting them to participate, and emails were re-sent to remind non-responders to participate on five occasions over a four-month period. Questionnaires used an online platform which students downloaded, completed and then returned via email. One staff member from UKZN who had not been involved in the GROWNUT project, received the completed questionnaires, anonymized them by allocating a study number and removing identifying information.

\section{Data analysis}

All questionnaires were double entered and validated in Excel 2019 and converted to SPSS V26 for analysis. Descriptive statistics are presented. Frequencies for rating of the master's programme and levels of agreement and disagreement with specific statements are shown in aggregated stacked bars. Where respondents reported a question as not applicable, the denominator was changed to reflect this. Open ended questions were categorized into themes and verbatim quotes used to highlight specific points and opinions.

\section{Results}

Data were collected between November 2019 and February 2020 . In total $35 / 40(88 \%)$ students responded to the questionnaire including respondents from each of the four cohorts.

Characteristics of respondents are shown in Table 3.

Most aspects of the Master Degree in Nutritional Epidemiology were rated as either good or very good. Aspects given a poor or very poor rating by a minority of the students were: the selection process for admission to the programme; external facilitators from GROWNUT partners; support provided during the rural internship; accommodation at the rural site; support for proposal development; support provided during data collection. (Fig. 1).

Agreement or disagreement with statements indicated how students experienced important aspects of the master's programme including how participating affected them personally (Fig. 2).

\section{English medium of instruction}

Most students (23/35) strongly agreed they benefitted from learning in English but a few remained neutral (3/ 35). While no student disagreed they had benefitted from learning in English, a small number of students (4/ 35) expressed that challenges of writing their thesis in English resulted in their being unable to submit an excellent thesis. Similarly, a few students (4/35) responded that they were unable to understand some topics discussed in the classroom because they did not understand English (Fig. 2).

\section{Financial/personal challenges}

Twenty two of the 35 students indicated they had encountered difficulties paying their bills or expenses while they were a student, and 20/35 students reported experiencing personal challenges while studying. Among 20 students who had received a bursary, 10 reported that the bursary was sufficient for their needs.

\section{Research skills development}

Collecting data in the rural research site was described as contributing towards a positive learning 


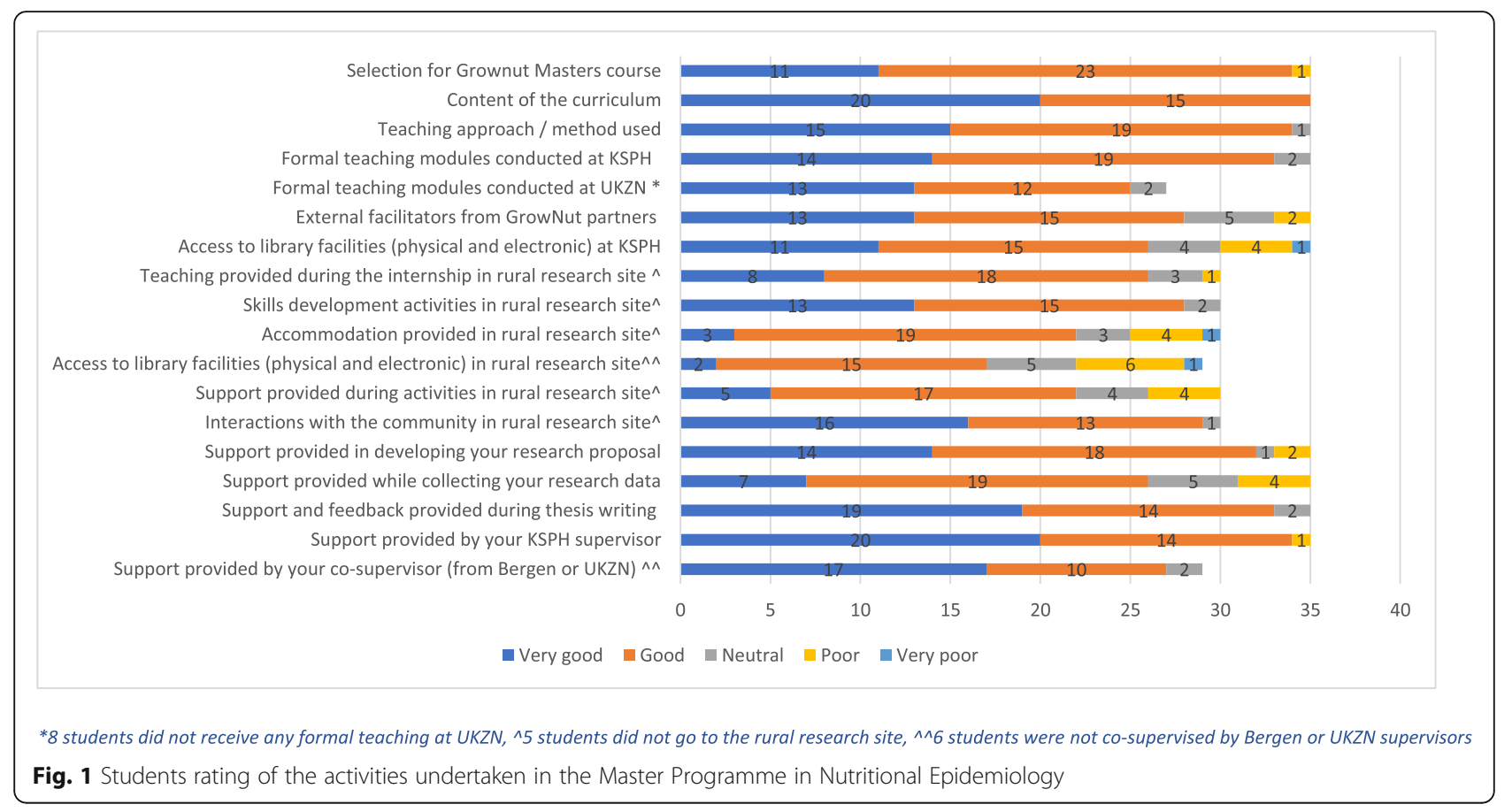

experience by most students (29/35). While all 35 students reported they had developed research skills that would benefit their future, and that supervisors provided timely feedback (35/35), there were a few (5/35) who communicated they had experienced challenges in coping with two supervisors for their research and would have preferred to only have one supervisor.

\section{Responses to open-ended questions}

Students used open-ended questions to describe the best and worst aspects of programme in their own words. Teaching methods used in the GROWNUT programme, learning in English, and experience gained at the rural research site were among the best aspects reported by students. Feeling isolated during the rural internship and financial difficulties were reported as worst aspects. In

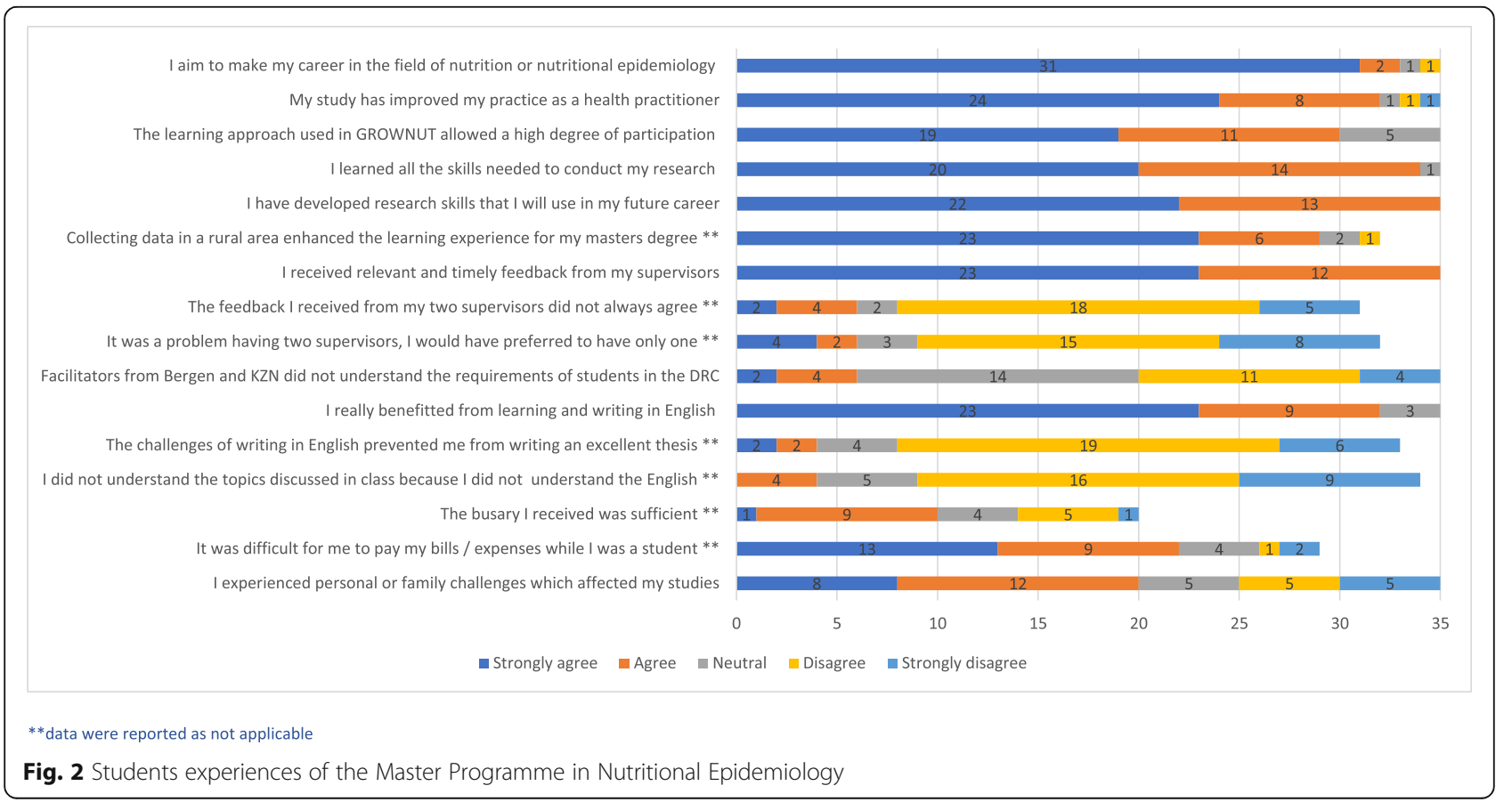


Table 3 Characteristics of participants

\begin{tabular}{|c|c|}
\hline & $n=35$ \\
\hline \multirow[t]{2}{*}{ Age of participants (median) } & 39 years \\
\hline & IQR 32-44 years \\
\hline \multicolumn{2}{|l|}{ Gender } \\
\hline Male & 23 \\
\hline Female & 12 \\
\hline \multicolumn{2}{|l|}{ Profession / Basic degree } \\
\hline Doctor / Medicine / Physician & 24 \\
\hline Nutritionist & 3 \\
\hline Other & 2 \\
\hline Missing data & 6 \\
\hline \multicolumn{2}{|l|}{ Cohort of GROWNUT students } \\
\hline 1st cohort & 7 \\
\hline 2nd cohort & 9 \\
\hline 3rd cohort & 9 \\
\hline 4th cohort & 8 \\
\hline Missing data & 2 \\
\hline \multicolumn{2}{|c|}{ Student participated in an internship in rural research site } \\
\hline Yes & 30 \\
\hline No & 5 \\
\hline \multicolumn{2}{|c|}{ Student collected data for thesis in rural research site } \\
\hline Yes & 26 \\
\hline No & 9 \\
\hline \multicolumn{2}{|l|}{ Degree is completed } \\
\hline Yes & 32 \\
\hline No & 3 \\
\hline \multicolumn{2}{|c|}{ Student received a GROWNUT bursary } \\
\hline Yes & 15 \\
\hline No & 12 \\
\hline Not applicable / missing data & 8 \\
\hline \multicolumn{2}{|c|}{ Language in which thesis was written } \\
\hline English & 29 \\
\hline French & 6 \\
\hline
\end{tabular}

addition, students gave a number of recommendations about how the programme could be improved (Table 4).

\section{Discussion}

To address the lack of research and academic leadership skills in health and nutrition in LMICs, we describe a successful nutrition-focussed educational approach that could be adapted for other postgraduate programmes. In DRC, a very-low income country [16], this approach increased the number of nutrition researchers, significantly strengthening academic leadership and research skills, with wider benefits outside of the nutrition field. Skilled researchers drive evidence-based research agendas and lobby for policy changes to improve important health indicators. We suggest collaborative projects among higher education institutions provide feasible solutions to address the skills gaps identified in research and research output in LMICs [9, 14, 15].

This project was positioned as a three-way NorthSouth-South partnership. Sustainability is a challenge for externally funded partnerships and our approach addressed this by increasing skills and confidence of local academic staff to take over delivery of the programme. Investing in $\mathrm{KSPH}$ academic staff has gone some way to promote sustainability, but the number of graduates has not reached critical mass yet. Partnerships are more likely to be successful and sustainable if maintained for periods longer than the normal five-year funding cycles. Longer funding periods would ensure ongoing support for novice programmes and create space for changes to occur, particularly in fluctuating academic landscapes where responses may be required to address changing disease patterns, epidemics and climate change. Achieving the skills to ensure sustainability requires long-term investment [23], and we contend there is still some way to go for $\mathrm{KSPH}$ to consolidate and build on what has been learned and achieved in this programme, whilst addressing challenges to effect transition from reliance on partner support to confidence, empowerment and independence.

Flexible training platforms [24], on-line learning methodologies [9] and blended learning approaches [13] are now more commonly used for teaching and learning as improvements to technology improves access for partners and students in LMICs. These approaches could address the high financial and human resource costs of extensive travel to and from partner countries, making North-South-South collaborations more cost effective. The set-up cost for on-line platforms may be high, but once established the platform will provide a range of opportunities to support teaching and learning and promote engagement with the scientific community, and in the longer term, may free resources for other important areas of educational programmes. Developing technology-based approaches that are supported by robust evidence of their quality and effectiveness is an important research need going forward.

In our study students were often constrained by financial and personal responsibilities, even those who received bursaries. Financial hardships, and even hunger, are not uncommon among university students [25-27], even in middle- and high-income countries, are therefore to be expected in a low-income country such as DRC, even among doctors and nutritionists who made up most of the student body. Despite being professionals, postgraduate students may have extensive financial and family responsibilities, making participation in 
Table 4 Students perceptions of the best and worst aspects of the Master Programme in Nutritional Epidemiology (open questions)

BEST things about GrowNut WORST things about GrowNut programme Students recommendations

\section{programme}

\section{Curriculum}

The content of the theoretical courses (GN10)

Epidemiology and Statistics courses were

much more advanced, compared to other

Master options (GN16)

Bio statistics and epidemiology (GN23)

Learning data entry and analysis software

(GN24)

Course contents were well designed.

(GN33)

Richness of the subject matter (GN34)

\section{Teaching methods}

Interactive teaching and to do homework in groups (GN04)

Facilitation of courses by teachers from

the universities of Bergen and KZN (GN05)

Benefit from teaching with rigorous

foreign teachers in their supervision.

(GN09)

Communication with certain facilitators

from different universities (GN11)

Experiences of the different local and

expatriate professors / facilitators (GN12)

Being taught by professors from other

countries university (GN15)

Knowledge sharing from Bergen /UKZN/

DRC facilitators (GN22)

Professors from "3 reality of the world"

(DRC, South Africa and Bergen /Norway).

(GN27)

\section{English language as a medium of instruction}

Learning courses and writing a thesis in English (GNO3)

The fact of writing my thesis in English (GNO9)

English. I have learnt new technical

vocabulary, new words and new

expressions (GN16)

Learning the lessons of the second block which was done entirely in English (GN17)

Different courses seen in practice and improved my English. (GN21)

Learning an important part of our study in English (GN26)

The course of high standards in English (GN27)

I gave myself a discipline to have extra classes in English. (GN 35)

\section{Bursaries}

Obtaining the scholarship, taking charge of my delivery, the payment of the child's nanny. (GN13)

Obtaining my scholarship (GN15)

Opportunity to get a scholarship. (GN20)
The qualitative research course was botched (GN11) Qualitative research module was not well provided (GN17)

Concentration of [too many] courses in one year. (GN33)

Studied for 2 years but transcripts are only for one-year Master (GN16)

Requirement to write, to be evaluated, to receive such relevant lessons and a thesis in a language that I do not master [English] (GNO6)

Poor English language skills have delayed some things (GN24)

Difficult to pay my bills while I was studying (GN20) The criteria set up to give the bursary for the PHD degree (GN27)

Not to have benefited from the scholarship (GN30)

Difficulties to pay academic fees for both years, without scholarship (GN35)
To add a behavioural communication module into the program, this will help prevent malnutrition at the community level (GNO7)

Deepen the qualitative research course (GN11)

A health communication course would be of great importance for the contact between the community and the researchers (GN13)

If we can add the courses in follow-up evaluation, project management and scientific communication (GN23)

Introduce a communication course in the programme and the development of emergency projects (GN24)

Reduce the training period to 18 months (GN05) To create openings within the framework of GrowNut continue my doctoral studies in epidemiology (GN08)

Increase the number of hours of field practice during the 1st year of internship (GN11)

There are modules that can be given in a conference setting (GN14)

Respect the time set for training (length of training). Training takes 27 months or more instead of 24 as planned (GN18)

Recommend that theoretical courses are given in 2 years instead of doing it in one year (GN31)

Introduce ... the English course 6 months before the start of the courses for capacity building (GN24)

Fair bursary distribution is required (GNO4) Increase the number of scholarships (GN05) provide life insurance / health insurance (GN11) Provide pocket money for scholarship learners (GN18) include in the bursary [selection] people who are not [resident] in the capital (GN29)

Feed external students, even with a meal, to increase their attention [span] during lessons (GN33) 
Table 4 Students perceptions of the best and worst aspects of the Master Programme in Nutritional Epidemiology (open questions) (Continued)

\begin{tabular}{|c|c|c|}
\hline $\begin{array}{l}\text { BEST things about GrowNut } \\
\text { programme }\end{array}$ & WORST things about GrowNut programme & Students recommendations \\
\hline \multicolumn{3}{|l|}{ The rural research site - internships } \\
\hline $\begin{array}{l}\text { Internship in Popokabaka. (GN01) } \\
\text { Participate in internship in Popokabaka. } \\
\text { (GN04) } \\
\text { Field work (training) in rural environment } \\
\text { (GN07) } \\
\text { Internship spent at Popokabaka, which } \\
\text { allowed the learners to contextualize the } \\
\text { theoretical lessons in the field. (GN08) } \\
\text { New experience working in the bush (on } \\
\text { the field) (GN15) } \\
\text { The internship of Popokabaka (GN17) } \\
\text { Practical course carried out in } \\
\text { Popokabaka which refined all the theory } \\
\text { learned for } 2 \text { years. (GN30) }\end{array}$ & $\begin{array}{l}\text { Lack of internship in organizations working on } \\
\text { nutrition and food security like UNICEF, Word Food } \\
\text { Program, FAO (GNO1) } \\
\text { No internship in research organizations or units } \\
\text { specializing in nutrition. (GN10) } \\
\text { The living conditions at POPOKABAKA were poor } \\
\text { (GN11) } \\
\text { Trip to Popokababka: a very bad road (GN12) } \\
\text { The indifference of the administrative team faced with } \\
\text { the difficulty encountered especially during internships } \\
\text { (GN26) } \\
\text { After the Popokabaka internship, I had the impression } \\
\text { that the department had abandoned us [no } \\
\text { communication on the rest of our programme] (GN17) }\end{array}$ & $\begin{array}{l}\text { Improve: accessibility to Popokabaka, accommodation } \\
\text { and catering conditions (GNO5) } \\
\text { To include internships in organizations interested in } \\
\text { nutrition such as WFP, UNICEF, FAO, etc., to enable } \\
\text { learners to become familiar with different types of } \\
\text { studies and approaches used by these organizations } \\
\text { (GNO9) } \\
\text { Diversify internship sites on the last year of internship } \\
\text { (GN11) } \\
\text { I would like learners be trained in rural area and in } \\
\text { united nations agencies (those working in nutritional } \\
\text { fields) for increasing [the] chance for job [s] (GN19) } \\
\text { If GROWNUT could contact some partners like WFP, } \\
\text { FAO, etc, for some internship time. }\end{array}$ \\
\hline
\end{tabular}

\section{Research experiences}

The workshop on research methodology (GN01)

Having two supervisors was a real challenge to face. (GNO3)

Increase the practical work on research and data analysis with all software (Stata) (GN24)

Mastering scientific research of nutritional problems, and data analysis software. (GN02)

The [research] workshop in KwaZuluNatal (GN17)

Improving my research skills (GN18)

Competence in research (GN19)

Learning of research methods (GN23)

Orientation towards to the research

(GN27)

Acquired the knowledge necessary to

conduct research with ease (GN28)

Improve my knowledge and skills in research (GN29)

post-graduate studies without financial support challenging. Funders often provide bursaries only for students designated as needy or based on merit, to avoid creating too much reliance on external funding, as in this project where funding was provided for a small number of students, and many applicants who did not receive a bursary withdrew as a result. Project funders should weigh the need to develop a critical mass of highly skilled qualified researchers against a reluctance to provide bursaries for a high proportion of students. We suggest that more bursaries at the start of the programme would allow it to become well established, and develop a large base of graduates to provide sustainability. The number of bursaries could then be reduced as the academic community becomes more able to sustain the process.

Most master's students responded well to the experience of spending several months in a rural area, working with the community and gaining practical experience. Embedding students from an urban-based university in a rural research site for practical learning and research was a novel approach aligned with the authentic learning approach, and differed from other master's programmes at KSPH or UNIKIN. Exposing or immersing medical students and other health professionals in rural areas has long been recommended as a way to recruit and retain health professionals in rural areas [28-30], and improve health worker coverage in remote areas [31]. Including a rural internship in a master's programme has a strong rationale but also has a number of challenges that need to be addressed if it is to achieve maximum benefits. Learning during the rural internship needs to be well structured, students need to be supported and logistic constraints considered. Some students reported inadequate support during their internship and this distracted from their rural experience. Students are vulnerable in an unfamiliar environment and need extra support to establish themselves and benefit from the experience. The extremely poor roads to the rural research site prevented students from travelling home during their internship, which enhanced their isolation but also allowed them to experience rural life, which some students really appreciated. It is important when choosing a rural site to consider this balance and ensure that it is feasible for students to receive the 
required support from academic staff. Students suggested increasing the number of internship sites to include placements with national and international nongovernmental organisations working in the nutrition field.

The use of English as the medium of instruction was a considered decision made by all partners, taking into consideration the wide-ranging benefits to the students and to the institution that have been observed in other settings [32]. Use of English was positively received and enhanced students' ability to access literature and create research networks. However, a few students struggled with learning and writing in English, which may have detracted from their experience of the course and their ability to perform academically. We agree with students that pre-enrolment English courses and additional support in communication and writing in English should be included in similar programmes in future.

An important output of the programme was to strengthen research capacity, and while students completed their research projects and a few students presented their findings at conferences, no master's student has thus far published their research. Writing articles for publication requires writing skills, dedicated efforts, time and on-going mentoring of young researchers but there also needs to be credible research to report. Future skills development programmes should provide enhanced support for writing for students and junior academic staff. In addition, data generated from studies did not lead to changes in nutrition policies. It is crucial to ensure that research findings are credible and communicated effectively to policy makers.

Nutrition challenges remain an ongoing concern in the DRC and it is unclear whether SDG 2 will be achieved. We propose that going forward a strong coherent nutrition research agenda based on local priorities is developed at KSPH, in partnership with PRONANUT, to which student research can contribute and which can explore solutions to the nutrition challenges affecting communities in DRC. Vibrant networks should be established both within the DRC and with other African countries findings disseminated to large and diverse audiences focussing applying findings to change policies.

\section{Strengths and weaknesses}

The strength of this evaluation is the good response rate. Self-administered questionnaires reduced interviewer bias and were available in both French and English allowing participants to freely express themselves. The findings from this study are specific to the programme described and therefore do not represent students in other programmes.

\section{Conclusion}

Early achievements and successes from this master's programme renews our commitment to health research capacity in resource constrained countries and universities through development of highly qualified academics and good quality academic programmes. The authentic learning pedagogy provided students with critical skills needed to advocate for the nutrition agenda in the DRC and provides a model for creating a teaching platform focusing on nutrition and research. However, creating capacity takes time and long-term funding is needed to build on early success and ensure sustainability of partnerships in higher education. Blended learning approaches may provide more cost-effective teaching and learning methodologies within North-South partnerships, but more research is required to establish their effectiveness.

\section{Supplementary Information}

The online version contains supplementary material available at https://doi. org/10.1186/s12909-021-02557-3.

Additional file 1: Supplementary File - Data collection tool.

Additional file 2

\section{Abbreviations}

$\mathrm{CIH}$ : Centre for International Health; CRH: Centre for Rural Health; DRC: Democratic Republic of Congo; FELTP: Field Epidemiology and Laboratory Training Programme; GROWNUT: Growing Partnership for Higher Education and Research in Nutritional Epidemiology; HSSREC: Humanities and Social Sciences Research Ethics Committee; JICA: Japan International Cooperation Agency; KSPH: Kinshasa School of Public Health; LMIC: LowMiddle income countries; MPH: Masters in Public Health;

NORHED: Norwegian Programme for Capacity Development in Higher Education and Research for Development; PRONANUT: Programme National de Nutrition (National Nutrition Programme / Ministry of Health, DRC); SDG: Sustainable Development Goals; SCONUTAL: Societé Congolaise de Nutrition et d'Alimentation; UKZN: University of KwaZulu-Natal;

UNIKIN: University of Kinshasa; UNICEF: United Nations International Child Emergency Fund; WFP: World Food Programme; WHO: World Health Organisation

\section{Acknowledgements}

We would like to thank all students who participated in the study. We would also like to acknowledge Dr. Marc Bosonkie from KSPH who assisted with the provision of student contact details and Mr. Sihle Mkize from $\mathrm{CRH}$ who anonymised the data.

We recognise and offer gratitude to our funders.

\section{Authors' contributions}

Data was analysed by LH. LH and $\mathrm{CH}$ wrote the first draft with significant input from MMA, SL, and SM. All authors reviewed and commented on the manuscript throughout the writing process (MMA, LH, VJ, AH, SL, SM, IE, TT, $\mathrm{PM}$, and $\mathrm{CH}$ ). All authors read and approved the final manuscript (MMA, LH, VJ, AH, SL, SM, IE, TT, PM, and CH).

\section{Funding}

Funding for the GROWNUT project including the evaluation was provided by the Norwegian Agency for Development Cooperation through the Norwegian Programme for Capacity Development in Higher Education and Research for Development (NORHED). 


\section{Availability of data and materials}

Data supporting the findings of this study are available from the principle investigator Centre for Rural Health (email: horwoodc@ukzn.ac.za) or as attached supplementary files.

\section{Ethics approval and consent to participate}

Ethical approval for this evaluation was obtained from University of KwaZuluNatal Humanities and Social Sciences Research Ethics Committee (HSS/0258/ 019), University of Kinshasa School of Public Health Ethics Committee (ESP/ CE/247/2019), and Norwegian Centre for Research Data (Ref 466503). Ethical principles and guidelines set out by the above mentioned research committees were followed throughout this study. All participants were appraised that returning the self-administered questionnaire meant they were providing informed consent therefore informed consent was obtained from all 35 participants who returned the questionnaire. Confidentiality and anonymity were ensured by allocation of a code which could not be linked to the participant.

\section{Consent for publication}

Not applicable.

\section{Competing interests}

We declare there are no competing interests.

\section{Author details}

'Kinshasa School of Public Health, University of Kinshasa, Kinshasa, Democratic Republic of Congo. ${ }^{2}$ Centre for Rural Health, School of Nursing and Public Health, University of KwaZulu-Natal, Durban, South Africa. ${ }^{3}$ School of Education, University of KwaZulu-Natal, Pietermaritzburg, South Africa. ${ }^{4}$ Centre for International Health, University of Bergen, Bergen, Norway. ${ }^{5}$ Fafo Institute for Labour and Social Research, Oslo, Norway.

\section{Received: 29 September 2020 Accepted: 25 January 2021}

\section{Published online: 27 February 2021}

\section{References}

1. Matenga TFL, Zulu JM, Corbin JH, Mweemba O. Contemporary issues in north-south health research partnerships: perspectives of health research stakeholders in Zambia. Health Research Policy and Systems. 2019;17(1):7.

2. WorldHealthOrganization: The world health report 2006: working together for health: World Health Organization; 2006.

3. JS CKM, Kyamanywa P, Ntakiyiruta G. Building Research Capacity in Africa: Equity and Global Health Collaborations. PLoS medicine. 2014;11(3): e1001612. https://doi.org/10.1371/journal.pmed.1001612.

4. Kok MO, Gyapong JO, Wolffers I, Ofori-Adjei D, Ruitenberg EJ. Towards fair and effective north-south collaboration: realising a programme for demand-driven and locally led research. Health Research Policy and Systems. 2017;15(1):96.

5. Kumpu M, Atkins S, Zwarenstein M, Nkonki L. A partial economic evaluation of blended learning in teaching health research methods: a three-university collaboration in South Africa, Sweden, and Uganda. Glob Health Action. 2016;9(1):28058.

6. Atkins S, Marsden S, Diwan V, Zwarenstein M. North-south collaboration and capacity development in global health research in low- and middleincome countries - the ARCADE projects. Glob Health Action. 2016;9(1): 30524.

7. Chastonay P, Zesiger V, Moretti R, Cremaschini M, Bailey R, Wheeler E, Mattig T, Avocksouma DA, Mpinga EK. A public health e-learning master's programme with a focus on health workforce development targeting francophone Africa: the University of Geneva experience. Hum Resour Health. 2015;13(1):68

8. Kellerman R, Klipstein-Grobusch K, Weiner R, Wayling S, Fonn S. Investing in African research training institutions creates sustainable capacity for Africa: the case of the University of the Witwatersrand School of public health masters programme in epidemiology and biostatistics. Health Research Policy and Systems. 2012;10(1):11.

9. Igumbor JO, Bosire EN, Basera TJ, Uwizeye D, Fayehun O, Wao H, Ajuwon A Otukpa E, Karimi F, Conco D, et al. CARTA fellows' scientific contribution to the African public and population Health Research agenda (2011 to 2018), BMC Public Health. 2020;20(1):1030.
10. Loukanova S, Prytherch H, Blank A, Duysburgh E, Tomson G, Gustafsson LL, Sié A, Williams J, Leshabari M, Haefeli WE, et al. Nesting doctoral students in collaborative north-south partnerships for health systems research. Glob Health Action. 2014;7(1):24070.

11. Heller RF, Strobl J, Madhok R. Online Education for Public Health Capacity Building in Low- to Middle-Income Countries: The Peoples-uni Experience. The International Review of Research in Open and Distributed Learning. 2019;20(1). https://doi.org/10.19173/irrodl.v20i1.3927.

12. Ihekweazu C, Ncube F, Schoub B, Blumberg L, Ruggles R, Salter M, Madhi S, Kessel A. A north/south collaboration between two national public health institutes - a model for global health protection. J Public Health Policy. 2015;36(2):181-93.

13. Protsiv M, Rosales-Klintz S, Bwanga F, Zwarenstein M, Atkins S. Blended learning across universities in a south-north-south collaboration: a case study. Health Research Policy and Systems. 2016;14(1):67.

14. Langer A, Díaz-Olavarrieta C, Berdichevsky K, Villar J. Why is research from developing countries underrepresented in international health literature, and what can be done about it? Bull World Health Organ. 2004;82(10):802-3.

15. McKee MSD, Basu S. Where there is no Health Research: what can be done to fill the global gaps in Health Research? PLoS Med. 2012;9(4):e1001209.

16. The World Bank in DRC. Available from https://www.worldbank.org/en/ country/drc. Accessed 12 Feb 2021.

17. UnitedNations. World Population Prospects 2019. In: Department of Economic and Social Affairs, Population Division United Nations; 2019.

18. USAID: Democratic Republic of the Congo: Nutrition Profile; 2018.

19. WorldDataAtlas: Infant mortality rate: World Data Atlas; 2018.

20. Herrington J, RTC, Oliver R. Authentic Learning Environments. In: MM SJ, Elen J, Bishop M, editors. Handbook of Research on Educational Communications and Technology. edn. New York, NY.: Springer; 2014. p. $401-12$.

21. Herrington J, Oliver R. An instructional design framework for authentic learning environments. Educ Technol Res Dev. 2000;48(3):23-48.

22. Cooperazionelnternationale: 260.000 malnourished children in Kwango province; 2019.

23. Lansang MA, Dennis R. Building capacity in health research in the developing world. Bull World Health Organ. 2004;82(10):764-70.

24. Amde WK, Sanders D, Lehmann U. Building capacity to develop an African teaching platform on health workforce development: a collaborative initiative of universities from four sub Saharan countries. Hum Resour Health. 2014;12(1):31.

25. Munro N, Quayle M, Simpson H, Barnsley S. Hunger for knowledge: food insecurity among students at the University of KwaZulu-Natal. Perspect Educ. 2013;31(4):168-79.

26. Payne-Sturges DC, Tjaden A, Caldeira KM, Vincent KB, Arria AM. Student hunger on campus: food insecurity among college students and implications for academic institutions. Am J Health Promot. 2018;32(2):34954.

27. Hattangadi N, Vogel E, Carroll $\sqcup$. Côté P: "everybody I know is always hungry ... but nobody asks why": university students, Food Insecurity and Mental Health. Sustainability. 2019;11(6):1571.

28. Wilson N, Couper I, de Vries E, Reid S, Fish T, Marais B. A critical review of interventions to redress the inequitable distribution of healthcare professionals to rural and remote areas; 2009.

29. Hill ME, Raftis D, Wakewich P. Strengthening the rural dietetics workforce: examining early effects of the northern Ontario dietetic internship program on recruitment and retention; 2017.

30. Hill ME, Raftis D, Wakewich P. Strengthening the rural dietetics workforce: examining early effects of the Northern Ontario Dietetic Internship Program on recruitment and retention. Rural Remote Health. 2017;17(1):4035. https://doi.org/10.22605/rrh4035. Epub 2017 Jan 27. PMID: 28125267.

31. Kapanda GE, Muiruri C, Kulanga AT, Tarimo CN, Lisasi E, Mimano L, Mteta K, Bartlett JA. Enhancing future acceptance of rural placement in Tanzania through peripheral hospital rotations for medical students. BMC Medical Education. 2016;16(1):51.

32. Dearden J. English as a medium of instruction-a growing global phenomenon. United Kingdom: British Council; 2014.

\section{Publisher's Note}

Springer Nature remains neutral with regard to jurisdictional claims in published maps and institutional affiliations. 